\title{
MEASURING TRANSIT-ORIENTED DEVELOPMENT LEVELS: A METHODOLOGICAL FRAMEWORK TO INCORPORATE THE USER INTO MODELLING
}

\author{
SARA M. IBRAHIM ${ }^{1,2 *}$, HANY M. AYAD ${ }^{1} \&$ DINA M. SAADALLAH ${ }^{1}$ \\ ${ }^{1}$ Department of Architecture, Alexandria University, Egypt \\ ${ }^{2}$ Department of Architecture, Delta University for Science and Technology, Egypt
}

\begin{abstract}
Worldwide, many cities have embraced the concept of transit-oriented development (TOD), as it is one of the most prominent approaches to land use and public transport integration. It is believed that measuring the existing TOD levels - 'TOD-ness' - of an area quantitatively is critical for TOD planning. However, a literature review reveals that spatial studies and quantitative methods that measure TOD-ness comprehensively are still limited and fragmented. Furthermore, recent research has opened the door to further investigation of methods and model development, which could bridge the gap between planning decisions and practical application. Due to the multidimensional aspects of the transport decision process and the involvement of many stakeholders, often with different points of view, the process has become more complex. Unfortunately, most of the spatial studies reviewed did not express the outcomes in terms of the impact on users, which can often prevent the realization of TOD implementation. To fill these knowledge gaps, this paper aims to suggest an integrated methodological framework that measures TOD-ness (including all stakeholders' perceptions) and also considers the users' opinions within their local context. The method developed extends from an existing framework commonly used by researchers, drawn from reviewing relevant studies published between 2000 and 2020. This paper reviews the studies in relation to TOD-ness measurement from a 'methodological focus', in which an overview of the dominant methods used is presented, in addition to their pros and cons. First, the paper introduces a theoretical review of the background of the concept, its evolution and the methods employed. An analytical review of the selected literature from different databases is then conducted. Finally, it is expected that the outcomes of the research will present the best-adopted methods and provide a developed model that measures TOD-ness quantitatively.

Keywords: transit-oriented development (TOD), TOD planning, TOD-ness, TOD level, TOD measurement, TOD index, multi-criteria decision making (MCDM).
\end{abstract}

\section{INTRODUCTION}

The transit-oriented development (TOD) concept appeared in the USA during the late 1970s and early 1980s. It received increasing attention from researchers and practitioners during the 1990s, when Peter Calthorpe published The Next American Metropolis in 1993. The concept aims to achieve sustainable development by merging transportation planning, landuse planning and urban design, providing holistic solutions to ongoing urban challenges. The literature is rich with various TOD definitions from many researchers such as [1]-[5] and many more. There is no general definition for the TOD concept because researchers and stakeholders describe it differently depending on their different perspectives. Altogether, the TOD concept is considered a way in which to increase transit ridership, densify neighbourhoods, promote compact and mixed-use developments, reduce auto dependence, reduce air pollution, encourage the use of non-motorized transport and maximize the efficiency of transport services by concentrating urban development around transit stations.

\footnotetext{
* ORCID: https://orcid.org/0000-0002-3715-7680
} 
Within this approach, it is necessary to measure the degree of TOD-ness for areas where the stakeholders, urban planners and decision-makers are interested in developing, building or maintaining. Accordingly, some researchers propose different methods, models and sets of indicators. However, it has been found that the spatial studies and quantitative methods that measure the degree of TOD-ness from a holistic vantage point are still limited and fragmented thus far. Further, due to the different perspectives on achieving or strengthening TOD, the intended aims of TOD change accordingly. Therefore, it has been found that some methods do not have standard frameworks and are barely operationalized, and they vary a little according to the research context and orientation.

After investigation, it was found that two approaches are addressed within TOD measurement research: (1) an approach that identifies the areas surrounding high-quality transit but where TOD levels are low and the transit orientation of those places need improvement; and (2) an approach that identifies potential locations for transit connectivity or areas that are characterized by high levels of TOD but poor or absent access to high-quality transit. The literature suggests that holistic location-based TOD-ness measurements had not been attempted before 2007. In a report by Evans et al. [6], the ten most commonly defined 'quantifiable' indicators to measure existing TOD levels were identified via an index. Later, Singh et al. [7] argued that a single TOD index is not sufficient, since the previously mentioned two approaches differ in terms of areas, scales and measurement indicators. Hence, they proposed two TOD indices for each approach, called the 'actual TOD index' and the 'potential TOD index'. These computable indices are usually analysed using multicriteria decision-making (MCDM) methods and techniques. The MCDM process is one of several different methods proposed since the 1970s to select an optimal solution for a given situation from a set of alternative decision criteria [8], and has been used in many fields as part of transportation planning. Accordingly, the paper's major orientation focuses on the second approach by reviewing the MCDM methods employed in identifying areas with high potential for successful investments in TOD.

As part of ongoing research, this paper aims to present the development of an integrated methodological framework for measuring existing TOD levels in an area-wide context. To achieve the paper's aim, the authors intend to meet the following objectives:

1. Reviewing the literature to identify possible gaps.

2. Facilitating further evolution of a framework based on the work that has been developed by others.

3. Helping decision-makers to identify priorities and offer a model to be used and assembled.

4. Presenting a vision of users' opinions during the decision-making process, in addition to how the proposed interventions fit their local and cultural contexts.

The structure of the paper consists of two main sections. The first section reviews the literature with a methodological focus, considering those studies published between 2000 and 2020 dedicated to the study of TOD measurement. The authors then identify the main gaps that will help in improving the existing methods, based on the literature analysis. The second section presents a five-stage modelling approach that verifies the structure of the proposed framework. 


\section{LITERATURE REVIEW}

\subsection{Literature analysis}

The literature time frame was chosen to limit our search based on the review conducted by Malczewski [9]. Malczewski's review revealed that the publishing of articles related to MCDM spatial methods such as spatial multi-criteria analysis (SMCA) had increased exponentially post-1995, with modest developments between 1990 and 1995 . Ultimately, a total of 13 eligible articles were identified for analysis, as shown in Table 1.

Table 1: The reviewed articles sorted by year of publication ascendingly. (Source: Authors.)

\begin{tabular}{|c|c|}
\hline Reference & Case study \\
\hline$[7]$ & - \\
\hline$[10]$ & SAN - NL \\
\hline$[11]$ & SAN - NL \\
\hline$[12]$ & SAN - NL \\
\hline$[13]$ & SAN - NL \\
\hline$[14]$ & SAN - NL \\
\hline$[15]$ & SAN - NL \\
\hline$[16]$ & Denver, US \\
\hline$[17]$ & Tehran, Iran \\
\hline$[18]$ & Tehran, Iran \\
\hline$[19]$ & (JMR), Indonesia \\
\hline$[20]$ & (JMR), Indonesia \\
\hline$[21]$ & New Jersey, US \\
\hline
\end{tabular}

Note: JMR = Jakarta Metropolitan Region; SAN = Stadsregio (City Region) Arnhem and Nijmegen; $\mathrm{NL}=$ Netherlands.

The reviewed literature shows that a variety of methods were used, divided between analytical methods and simulation-based methods. A number of analytical techniques were obtained by grouping them under four main categories (suitability analysis, hierarchal decision process, statistical analysis and visual analysis), as shown in Table 2. Among the most reliable methods were suitability analysis techniques - especially multi-criteria decision analysis techniques - followed by spatial statistical and then the hierarchal decision process. The models were also classified into four main categories (geographic information system (GIS)-based, analytic hierarchy process (AHP)-based, statistical-based and agent-based models). The dominant model used was the GIS-based model, which accounted for $92.3 \%$ $(\mathrm{n}=12)$ of the total studies. Only study [16] used an AHP-based model without employing GIS. The research by Motieyan and Mesgari [18] was the only study that used an agent-based model, and thus being classified as a simulation-based method. Much more common were studies that used combined methods, which accounted for $92.3 \%(n=12)$ of the total studies. Furthermore, most of the reviewed studies used TOD index scores to measure the TOD-ness of an area, but with different methodological frameworks. A mix of spatial and non-spatial indicators, which are measurable and quantifiable at the same time, were used to calculate such indexes. 
Table 2: The studies with respect to the employed method. (Source: Authors.)

\begin{tabular}{l|c|}
\hline Method/Technique & Included in the study \\
\hline Suitability analysis & {$[7],[10]-[15],[17]-[21]$} \\
\hline Hierarchal decision process & {$[16],[17],[19],[20]$} \\
\hline Statistical analysis* & {$[10]-[21]$} \\
\hline Visual analysis** & {$[7],[10]-[15],[17]-[21]$} \\
\hline Combined method*** & {$[7],[10]-[15],[17]-[21]$} \\
\hline *Either spatial or non-spatial analysis. \\
**Either spatial analytical or spatial statistical that can facilitate interpreting \\
spatial index. \\
***Much more common are the studies that used combined methods.
\end{tabular}

To calculate the potential TOD index, it was found that many researchers employed SMCA techniques. The review reveals that the study by Singh et al. [7] proposed the SMCAmethodological framework, considered an extension of the work of [6]. Likewise, a number of studies [10]-[15] 'operationalized' or 'developed' the same SMCA-based framework of [7], using spatial statistical analysis with the combined spatial models of GIS. The studies from [16]-[18] used the AHP-MCDM method in developing a decision support system (DSS) framework. Finally, the works of [19], [20] used spatial statistical analysis with combined models of GIS and AHP. The researchers admitted that the potential TOD index map could only be used to either make a comparison between locations in order to identify the transit-oriented location with the most potential, but without clarifying the magnitude of the differences, or provide us with different values, but without indicating the required actions in practice. Thus, almost all of the reviewed studies employed spatial statistical analysis except [16], which employed statistical analysis only. Furthermore, these studies investigated the statistics of spatial association through 'spatial clustering', using global or local cluster statistics methods.

\subsection{Methodological pros and cons}

The review reveals that many researchers considered SMCA the preferred analytical method for prioritizing potential locations for interventions, due to stakeholder participation twice in the SMCA process: first, their major role in assigning the weights to each indicator before calculating the TOD index, and second when discussing the TOD indices. Moreover, stakeholder bias can be eliminated after performing a sensitivity analysis to test the small change in weights in the TOD scores.

Furthermore, the methodological framework adopted by [10]-[15] has obvious strengths: (1) it can quantitatively measure the TOD-ness of an area via a TOD index across an entire area; (2) it is transparent and back-traceable; (3) it is simple, which makes it repeatable; (4) it can identify whether an area is moving towards or away from performance threshold values; (5) studies that use spatial statistical analysis lead to higher accuracy in results; and (6) the results provide an input for the SDSS environment and can then be assessed by stakeholders in order to propose planning interventions in those areas. The AHP-MCDM framework adopted by [16]-[20] has also helped in suitability analysis and decision making. It is considered a robust multi-criteria methodology: (1) it can simplify the decision problem into a hierarchical arrangement (i.e. criteria and sub-criteria); (2) the weights of the criteria are determined utilizing pairwise comparisons; (3) it determines the local weight and overall 
weight for each criterion; (4) it produces the TOD index from multiple stakeholders' points of view; and (5) in contrast to other multi-criteria methods, it computes the consistency index of decision-makers' opinions on the importance of the criteria.

However, weak points were found in some studies, such as that by Fard [10], which determined the potential TOD index for the entire area regardless of whether or not the area had transit access. Therefore, the consideration of some transit system elements was missed in this study. Further, some studies [11]: (1) did not propose scenarios for improving the TOD-ness of areas in the region, especially public transit service areas that had the potential for development; (2) did not consider accessibility or street connectivity, which are considered efficient indicators in developing a TOD index; or (3) computed the indicators in a raster format, which is considered improper in urban planning, as some errors may potentially result. Another drawback was noticed regarding the criteria weighting, which was determined by a small number of stakeholders or was not representative of the whole list of stakeholders. Furthermore, the analysis of the reviewed publications showed four main gaps, as discussed in Table 3. Based on these gaps, it can be seen that: (1) the models need improvement to involve stakeholders per actor in the decision process, especially in regard to 'actor-oriented research'; and (2) there is a necessity to develop 'context-based' models, where the societal way of life and public opinion penetrate the policy-making process.

Table 3: The gaps found from reviewing the literature. (Source: Authors.)

\begin{tabular}{|l|l|}
\hline Gap 1 & $\begin{array}{l}\text { The weighting scores in the decision process and the resulting data were at } \\
\text { a global level (for all stakeholders) not per actor. }\end{array}$ \\
\hline Gap 2 & $\begin{array}{l}\text { Most of the spatial studies did not express the outcomes in terms of the } \\
\text { impact on users, thus neglecting the number or percentage of the users. }\end{array}$ \\
\hline $\begin{array}{l}\text { Improvement on gap 1 and gap 2: The models need improvement to involve } \\
\text { stakeholders per actor in the decision process, especially 'actor-oriented research'. }\end{array}$ \\
\hline Gap 3 & $\begin{array}{l}\text { The lack of models investigating the existing obstacles (i.e. social reality) } \\
\text { can prevent the realization of TOD when shifting from theory to practical } \\
\text { application, especially in developing countries (theory-practice gaps). }\end{array}$ \\
\hline Gap 4 & $\begin{array}{l}\text { The role of urban structures, the relative attractiveness and the adequacy } \\
\text { of the transport mode at the proposed locations were not considered, while } \\
\text { the effects of urban density were overestimated. }\end{array}$ \\
\hline $\begin{array}{l}\text { Improvement on gap 3 and gap 3: there is a necessity to develop a 'context-based' } \\
\text { model where the societal way of life and public opinion penetrate the policy-making } \\
\text { process. }\end{array}$ \\
\hline
\end{tabular}

\section{FINDINGS}

Arguably, the review revealed that the findings of the previous studies could not be compared to identify their potential degrees of success in the future due to the diversity of the methods employed. Hence, without comparison or validating scores, it is difficult to know which method would produce the best results. The literature has provided a few studies, such as those by [12], [16], [18], that suggest which policies are needed for improvements or suggest a detailed TOD site decision based on the results. However, some researchers claimed that planners will still need more information on land use plans, optimum actions or political motivations to make physical plans when the need arises. The review also revealed that the 
PSS-based framework in many studies cannot predict or simulate how increases in density, jobs or economic development would affect the number of transit users (commuters).

Concerning stakeholder involvement, their opinion was often used twice in the reviewed studies: (1) at the very first stages of the SMCA in order to assign criteria and indicator weights to build an initial framework; and (2) at the end of the analysis, when stakeholders were asked to provide 'feedback' on the results of the analysis, allowing a robust sensitivity analysis to be performed. This type of involvement, in most cases, completed the decision process and created a flexible procedural cycle. However, this cannot be predicted to achieve the optimum action plans or TOD planning interventions with respect to users or their satisfaction, preferences and behavioural intentions in the future.

\subsection{Adopted framework: A five-stage modelling approach}

According to the discussion above, TOD planning requires a robust method that can handle top-down and bottom-up procedures. Based on the review, the most frequently adopted framework proposed by [7], [12] can be easily implemented in the decision-making models and be extended towards a complete methodology. Therefore, a five-stage methodological framework was developed in order to extend and reform the framework of [7], [12], allowing for a more participatory approach. It aims to obtain the realization of TOD when shifting from theory to practical application, especially in developing countries and in relation to their turbulent realities. This framework is comprised of three combined models: SMCA-based, GIS-based and context-based models. It is defined in a hierarchical manner, where both multiple stakeholders and users have equal involvement in the process. The first four stages are applied through a 'multi-actor multi-criteria analysis (MAMCA)' and the fifth stage through a 'per-actor (user) analysis'.

First, the framework quantitatively measures TOD-ness (based on multiple stakeholders' viewpoints) using spatial analytical tools (e.g. ArcGIS and ILWIS). Second, the TOD index values are analysed using spatial statistical analysis to identify the level of clustering (cluster analysis) in the GIS environment. As illustrated in Fig. 1, Global Moran's I statistic is employed to determine the cluster locations and their significance. Then, local cluster statistics (Getis-Ord Gi* statistic, Anselin Local Moran's I index and Anselin Local Indicators of Spatial Association (LISA)) are employed to analyse spatial patterns and locations of actual clusters. Third, the TOD index results can be used in the SDSS environment, where multiple stakeholders can identify the specific TOD planning interventions needed for the TOD-ness improvement of each location in an area. This creates different development scenarios for different weights, and each scenario will have a separate TOD index map.

At the final stage, the framework considers the explicit inclusion of the current/potential users in relation to the importance/satisfaction measurement of these scenarios, based on their preferences, local and cultural context, and complex social settings. This kind of measurement can assist decision-makers in identifying user demand, desired ends and desired quality, and can be applied in focus group discussions, in-depth interviews or separate questionnaires for the users. To provide a better understanding of each stage, the framework is shown in Fig. 2 in detail. This kind of measurement has been used before in Mohamed et al. [22] s' framework as an integral element that monitors bus service quality within the context of the United Kingdom. However, their framework addressed traditional quality parameter and system performance parameters in a combined single output measurement model. 


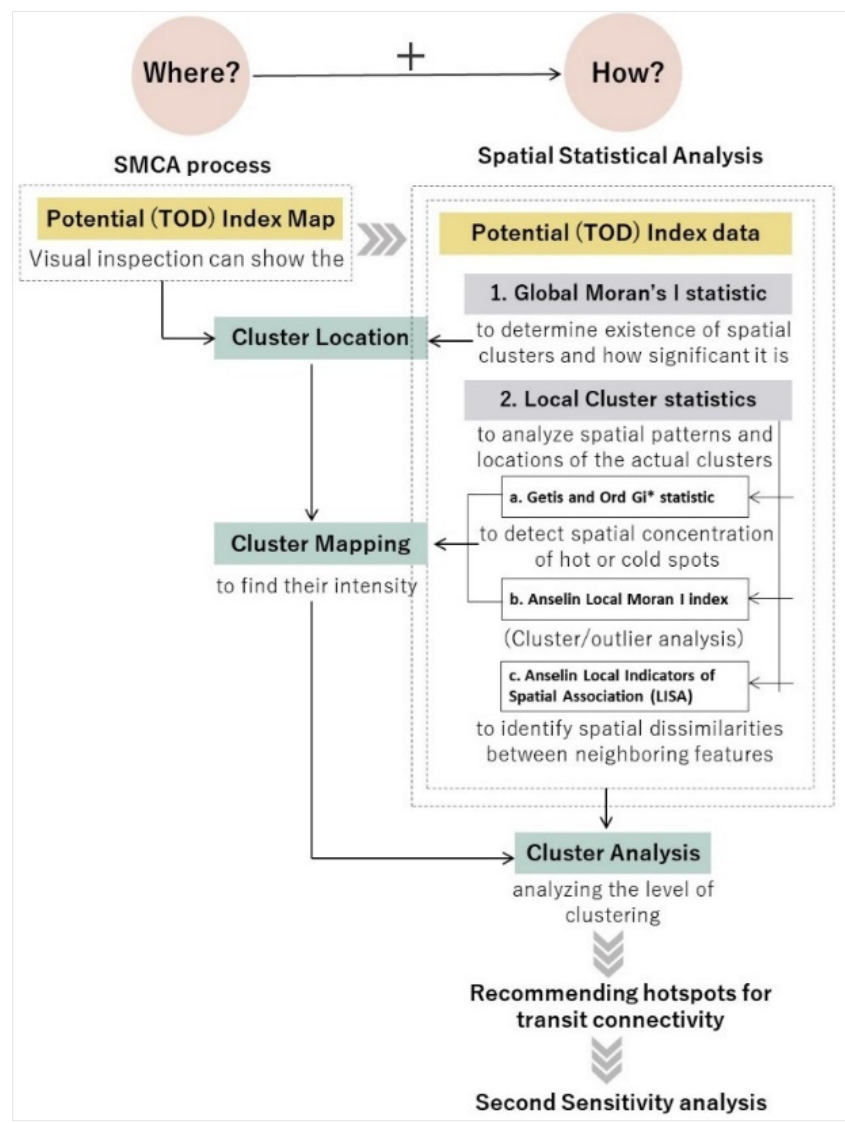

Figure 1: The detailed description of stage 3 that analyses TOD index values. (Source: Authors.)

Multi-Actor Multi-Criteria Analysis (MAMCA)

Per-Actor (User) Analysis

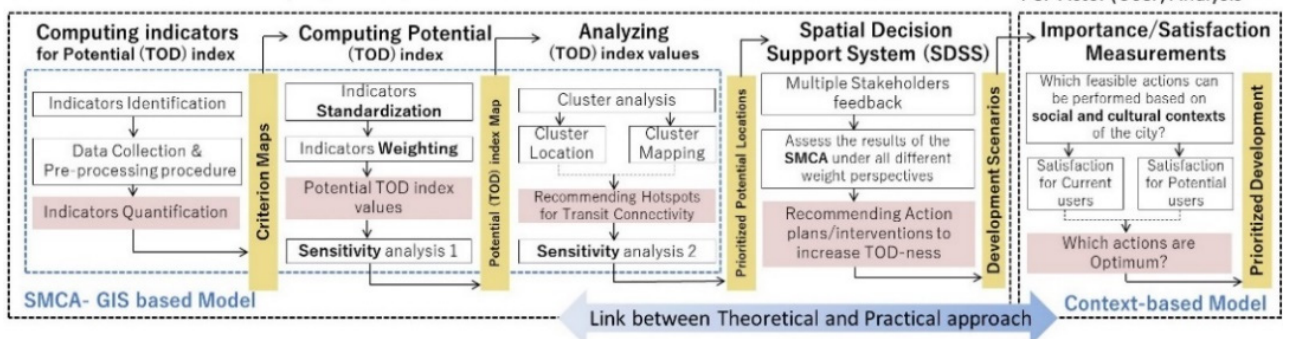

Figure 2: The integrated methodological framework. (Source: Authors.)

The designed framework can: (1) quantitatively measure the TOD-ness of a specific area via a TOD index across an entire area; (2) identify the potential locations for intervention in TOD planning; and (3) analyse TOD index values using spatial statistical analysis to identify 
the level of clustering. The results provide an input for the SDSS environment and can then be assessed by stakeholders in order to propose planning interventions in those areas. It also involves the current/potential users to establish the importance/satisfaction measurement of these scenarios in order to identify the optimum actions.

\section{CONCLUSON}

Worldwide, TOD has received much attention, in both the research community and in relation to actual city development. It is believed that measuring the TOD-ness of an area quantitatively is critical for effective TOD planning. This review revealed that there are insufficient spatial studies and quantitative methods that measure TOD-ness in order to identify potential locations for transit connectivity in an area-wide context. Furthermore, published articles on this topic have been more observable since 2010. It has been acknowledged that achieving effective TOD requires more involvement and cooperation between planners, decision-makers, private investors and other stakeholders. However, the stakeholders' different points of view have made the decision process more complex. Consequently, the selection of proper measurement methods needs more consideration, because without measuring the TOD-ness outcomes correctly, mistakes in investment strategy will occur repeatedly.

It was found that almost all the researchers encouraged developing a TOD index that can quantify TOD-ness. With respect to the methods employed, combined methods using suitability analysis (SMCA) and spatial statistical analysis techniques have been predominantly used in TOD measurement studies. At the same time, the authors of a few studies employed agent-based, AHP-based and statistical-based models in their work. Unfortunately, most of the spatial studies did not express the outcomes in terms of the impact on users, which could often prevent the realization of TOD implementation. Further, it is believed that the users' separate participation encourages the bottom-up approach in both planning and decision-making processes. Therefore, this paper has developed a framework that can quantitatively measure the TOD-ness of an area while ensuring practical and socially acceptable proposals for the users. The results of the SMCA are first assessed by multiple stakeholders in a transparent SDSS environment, and they then propose the different development scenarios that have the most potential for being implemented. Finally, the framework incorporates current/potential users, who can choose from the proposed planning actions and interventions by evaluating their satisfaction, priorities and demands. This type of measurement can have a valuable impact on real-world practices, especially in developing countries. In terms of further research, work on implementing the framework developed in this paper is planned as one of the next steps in our research.

\section{REFERENCES}

[1] Belzer, D. \& Autler, G., Transit-Oriented Development (TOD): Moving from Rhetoric to Reality, USA, pp. 1-46, 2002. www.brookings.edu/urban.

[2] Cervero, R., Arrington, G.B. \& Dunphy, R., Transit-oriented development (TOD) in the United States: Experiences, challenges, and prospects - TCRP Report 102. Washington, DC, 2004. http://nap.edu/23360.

[3] Cervero, R. \& Kockelman, K., Travel demand and the 3Ds: Density, diversity, and design. Transport Research Part D Transport Environmental, 2(97), pp. 199-219, 1997. DOI: 10.1016/S1361-9209(97)00009-6.

[4] Schlossberg, M. \& Brown, N., Comparing transit-oriented development (TOD) sites by walkability indicators. Transportation Research Record: Journal of the Transportation Research Board, 1887, pp. 34-42, 2004. DOI: 10.3141/1887-05. 
[5] Ewing, R. \& Cervero, R., Travel and the built environment: A synthesis. Transportation Research Record. Journal of the Transportation Research Board, pp. 87-114, 2001. DOI: 10.3141/1780-10.

[6] Evans, J.E., Pratt, R.H., Stryker, A. \& Kuzmyak, J.R., Transit oriented development: traveler response to transportation system changes handbook. TCRP Report 95, Transport Research Board of the National Academies, Washington, DC, pp. 1-138, 2007.

[7] Singh, Y., Zuidgeest, M.H.P., Flacke, J. \& van Maarseveen, M.F.A.M., A design framework for measuring transit oriented development. WIT Transactions on the Built Environment, vol. 128, WIT Press: Southampton and Boston, pp. 719-730, 2012.

[8] Shastry, S., Spatial assessment of transit oriented-development (TOD) in Ahmedabad, India [Internet]. Faculty of Engineering Technology, Civil Engineering and Management, University of Twente, Netherlands, 2010. http://purl.utwente.nl/essays/ 59707.

[9] Malczewski, J., GIS-based multi-criteria decision analysis: A survey of the literature. International Journal Geographical Information Science, 20(7), pp. 703-726, 2006. DOI: $10.1080 / 13658810600661508$.

[10] Fard, P., Measuring transit oriented development (TOD): Implementing a GIS-based analytical tool for measuring existing (TOD) levels. University of Twente, Faculty of Geo-Information Science and Earth Observation (ITC), Netherlands, 2013. https://webapps.itc.utwente.nl/librarywww/papers_2013/msc/upm/fard.pdf.

[11] Singh, Y.J., He, P., Flacke, J. \& van Maarseveen, M., Measuring transit-oriented development (TOD) over a region using an index. ResearchgateNet, 2014. https://www.researchgate.net/profile/MFAM_Maarseveen/publication/290433256_M easuring_Transit_Oriented_Development_over_a_region_using_an_index/links/56 97 ad0008ae1c4279050f14.pdf.

[12] Singh, Y.J., Fard, P., Zuidgeest, M., Brussel, M. \& van Maarseveen, M., Measuring transit oriented development: A spatial multi criteria assessment approach for the City Region Arnhem and Nijmegen. Journal of Transport Geography, 35, pp. 130-143, 2014. DOI: 10.1016/j.jtrangeo.2014.01.014.

[13] Singh, Y.J., Lukman, A., Pengwei, H., Flacke, J., Zuidgeest, M. \& van Maarseveen, M. Planning for transit oriented development (TOD) using a TOD index. 2015. https://www.researchgate.net/publication/290432243.

[14] Singh, Y.J., Measuring transit-oriented development (TOD) at regional and local scales - A planning support tool. University of Twente, Faculty of Geo-Information Science and Earth Observation (ITC), Netherlands, 2015.

https://webapps.itc.utwente.nl/librarywww/papers_2015/phd/singh.pdf.

[15] Singh, Y., He, P., Flacke, J. \& van Maarseveen, M., Measuring (TOD) over a region using GIS based multiple-criteria assessment tools. SPA Journal Scholar Plan Architecture, 19, pp. 1-22, 2015.

https://www.researchgate.net/publication/302985264.

[16] Strong, K., Ozbek, M., Sharma, A. \& Akalp, D., Decision support framework for transit-oriented development (TOD) projects. Transportation Research Record: Journal of the Transportation Research Board, 2671, pp. 51-58, 2017.

[17] Motieyan, H. \& Mesgari, M.S., Towards sustainable urban planning through transitoriented development (A case study: Tehran). ISPRS International Journal of GeoInformation, 6, pp. 1-16, 2017. 
[18] Motieyan, H. \& Mesgari, S.M. An agent-based modeling approach for sustainable urban planning from land use and public transit perspectives. Cities, 81, pp. 91-100, 2018. DOI: 10.1016/j.cities.2018.03.018.

[19] Taki, H.M. \& Maatouk, M.M.H., Spatial statistical analysis for potential transit oriented development (TOD) in Jakarta Metropolitan Region. Journal of Geoscience Engineering Environmental Technology, 3(1), p. 47, 2018.

[20] Taki, H.M. \& Maatouk, M.M., Spatial planning for potential green (TOD) using suitability analysis at the metropolitan region scale. IOP Conference Series: Earth and Environmental Science, IOP Publishing, 2018.

[21] Semeraro, L., Approaches to transit-oriented development (TOD): How existing infrastructure can lend itself to implementation of transit oriented development techniques. Graduate School of Architecture Planning and Preservation, Columbia University, New York, 2018.

[22] Mohamed, M., Hine, J. \& Kashyap, A., Bus transit service quality monitoring in UK: A methodological framework, 2011. 